\title{
PROPERTIES OF OSB PANELS WITH VENEER INCLUSION
}

\author{
Rafael Farinassi Mendes ${ }^{1, \uparrow}$, Antônia Amanda da Silva César ${ }^{1}$, Marcela Gomes da Silva ${ }^{1}$, \\ Lourival Marin Mendes ${ }^{2}$, Amélia Guimarães Carvalho ${ }^{3}$
}

\begin{abstract}
This work aimed to evaluate the effect of veneer inclusion with different wood species, and also different levels of pressing pressure applied in the moment of the veneer inclusion over physicalmechanical properties of already consolidated OSB (Oriented Strand Board) panels. Treatments were arranged in factorial scheme 4 x 2 (four wood types for veneer inclusion - Pinus oocarpa, Eucalyptus urophylla, Parkia gigantocarpa and Brosimum parinariodes; and two pressing pressures -1 and 2 $\mathrm{MPa}$ ) and also a control (without veneer inclusion). Veneer inclusion was made with $180 \mathrm{~g} . \mathrm{cm}^{-2}$ phenol formaldehyde adhesive, in a simple glue line, perpendicular to the external layer of panels. The pressing cycle used was $150^{\circ} \mathrm{C}$ for 4 minutes under pressure 1 or $2 \mathrm{MPa}$ pressure depending on the pre-established treatment. It was possible to conclude that: 1) Veneer inclusion with pines, eucalypt and amapá promoted significant improvements for physical-mechanical properties of OSB panels, highlighting eucalypt and amapá; 2) There was not a significant effect of the level of pressing pressure over mechanical properties of OSB with veneer inclusion; and 3) Regarding physical properties, the highest pressure level (2 MPa) promoted a negative effect in some properties, while veneer inclusion the pressure of $1 \mathrm{MPa}$ generally promoted significant improvement of all physical properties.
\end{abstract}

Keywords: Brosimum parinarioides, Eucalyptus urophylla, oriented strand board, mechanical properties, Parkia gigantocarpa, physical properties, Pinus oocarpa, veneer inclusion.

\section{INTRODUCTION}

The panels OSB (Oriented Strand Board) are produced from strand type particles (thin and long), and the internal layer may be randomly placed or perpendicular to the external layers. Such panels are mainly used as structural components, such as walls, beam components, lining, among others, competing with plywood panels for space.

The mechanical strength of OSB panels is usually similar to the plywood (Tsoumis 1991). However, its main limitation is the low dimensional stability, since OSB when in contact with moisture presents greater thickness swelling than plywood (Mendes et al. 2013). Furthermore, it is considered by some consumers as a lower quality panel in relation to the surface finishing. But even with such limitations, the production of OSB panels has grown significantly and occupied spaces which were exclusive to plywood. This is explained by the possibility to be produced from thinning wood and with thin trunks, as well as from species with lower commercial value, besides a greater use of the log, which allows lower costs (Walker 1993).

\footnotetext{
Doctor candidate in Wood Science and Technology, Federal University of Lavras/UFLA, Lavras. Brazil. amanda_ufla@hotmail.com; marcela.gsilva@gmail.com

${ }^{2}$ Professor in the Department of Forest Sciences, Federal University of Lavras /UFLA. Lavras. Brazil. lourival@dcf.ufla.br

${ }^{3}$ Master candidate in Wood Science and Technology, Federal University of Lavras/UFLA. Lavras. Brazil. ameliagcarvalho@gmail.com

• Corresponding author: rafaelfarinassi@gmail.com

Received: 10.07.2013 Accepted: 23.07.2015
} 
Thereby, in order to associate lower production costs with better quality panels, several researches have been developed aiming to improve dimensional stability of OSB panels (Garcia et al. 2005, Cabral et al. 2006, Del Menezzi and Tomaselli 2006, Paul et al. 2006, Okino et al. 2007, Mendes et al. 2013a, Mendes et al. 2013b).

Veneer inclusion consists of a technique with potential to improve the dimensional stability of particulate panels, which is commercially denominated Com-ply (Maloney 1996), process that comprises the bonding of wood veneers with synthetic adhesive and adequate pressure in the panel surface, aiming to decrease the water entrance through the surface and consequently the thickness swelling, thus increasing the resistance and hardness of flexion (Iwakiri et al. 2003), which can improve the surface finishing of OSB panels.

Iwakiri et al. 2009, studied the effect of veneer inclusion in OSB panels, the results showed no significant reductions of water absorption and thickness swelling for the panels with veneer inclusion. In relation to modulus of elasticity (MOE) and rupture (MOR), in perpendicular direction, they observed significant improvements. Contrarily, Mendes et al. 2012, when evaluating veneer inclusion of OSB panels from Pinus oocarpa, observed significant improvements of the water absorption properties and thickness swelling after two hours of immersion.

However, the few available researches are related to the veneer inclusion through the process of panels pressing, which means the veneer inclusion in the moment of its consolidation. There are not studies regarding veneer inclusion of the already consolidated panel. Considering that in the industry it is not possible to include wood veneers during the OSB panels pressing, it is important to evaluate the effect of veneer inclusion after being consolidated, particularly because many resales buy such panels just to cover externally and then hand over to the consumers.

Another factor that also needs assessment is the type of wood used to veneer inclusion, since depending on their chemical, physical, anatomical and mechanical characteristics can significantly influence the properties of the coated panel. As an option for inclusion veneer can be evaluated the use of species planted on a large scale in Brazil, such Pinus oocarpa and Eucalyptus urophylla, or the Amazon woods, with wide dispersion and good qualities esthetics, such as wood of Parkia gigantocarpan (faveira) and Parinarioides brosimum (amapá).

In this context, this work aimed to evaluate the effect of veneer inclusion with different wood species (Pinus oocarpa, Eucalyptus urophylla, Parkia gigantocarpa, Brosimum parinarioides), and also different levels of pressing pressure applied ( 1 and $2 \mathrm{MPa}$ ) in the moment of the veneer inclusion over physicalmechanical properties of already consolidated OSB panels.

\section{MATERIAL AND METHODS}

Commercial OSB panels $15 \mathrm{~mm}$ thick were used in the present study, with 4,5\% of phenolformaldehyde; $0,9 \%$ paraffin, relation surface: core of $50: 50$ and apparent density of $610 \mathrm{~kg} . \mathrm{cm}^{-3}$. The experimental design consisted of nine treatments, with the evaluation of the four wood types (Pinus oocarpa, Eucalyptus urophylla, Parkia gigantocarpa, Brosimum parinarioides) in association with two pressing pressure ( 1 and $2 \mathrm{MPa}$ ) and um treatment without veneer inclusion (control). For each treatment three repetitions were used. 
The species Parkia gigantocarpa Ducke (Faveira) and Brosimum parinarioides Ducke (amapá) came from an area of forest management in the municipality of Paragominas - PA, which belongs to the company Cikel Brasil Verde S/A.

The wood of Eucalyptus urophylla, seven years old, was obtained from clonal tests settled in the city of Paracatu - MG, while the wood of Pinus oocarpa, 35 years old, was obtained from the Universidade Federal de Lavras - MG.

Disks were removed from each species, which were used to determine the basic density according to the standard NBR 11941 (ABNT, 2003) and also to perform chemical analysis, with the content of total extractives (NBR 14853, 2010), lignin (NBR 7989, 2010), ashes (NBR 13999 2003) and holocellulose (obtained by the difference H $(\%)=100-\%$ total extractive - \%lignin - \% ashes).

Logs of different species, after being sectioned in adequate length, were taken to a heating tank, where they were kept at $66^{\circ} \mathrm{C}$ during $24 \mathrm{~h}$. Faveira wood did not pass through this proceeding due to its low density.

After this period, logs were processed in a veneer lathe, creating $2 \mathrm{~mm}$ thick sheets which were posteriorly guillotined in the dimensions of $50 \times 50 \mathrm{~cm}$, and then dried in stove at $70{ }^{\circ} \mathrm{C}$ until the moisture was between 5 and $6 \%$. Before plywood manufacture, dried sheets were classified in decreasing quality classes (A, B , C, D) according to the Brazilian Standard NBR 9531 - Sheets of Plywood: Classification, of the Brazilian Association of Technical Standards (ABNT 1986). In the present study, only sheets classified as B panels were used for veneer inclusion.

The veneer inclusion of OSB panels was made with phenol-formaldehyde adhesive with solid content of $51,24 \%$; $\mathrm{pH} 11,89$; gel timer of 8,41 minutes and viscosity of $547 \mathrm{cP}$. The collage of the veneers was performed at the two surface of the panels, with $180 \mathrm{~g} \cdot \mathrm{m}^{-2}$ adhesive in simple glue line and perpendicularly the surface particles. After this stage, panels were hot-pressed with a pressing cycle at $150^{\circ} \mathrm{C}$ during 4 minutes and pressure 1 or $2 \mathrm{MPa}$, depending of the pre-established treatment.

After veneer inclusion, they were conditioned at $22 \pm 2^{\circ} \mathrm{C}$ and relative moisture of $65 \pm 5 \%$. The dimensions of body-proof and essay proceedings applied in the evaluation of the properties water absorption (WA) after two and twenty four hours of immersion, thickness swelling (TS) after two and twenty four hours of immersion and rate of non-return in thickness (NRT), were defined based on the American Standard ASTM D 1037 (2006). The standard DIN 52362 (1982) was applied to evaluate rupture modulus (MOR) and elastic modulus (MOE) to static flexion in parallel and perpendicular directions in relation the surfaces veneers.

An entirely randomized design was adopted to analyze results, in which treatments were arranged in a factorial scheme $4 \times 2$ (four types of wood - faveira, amapá, eucalypt and pines; two pressing pressures -1 and $2 \mathrm{MPa}$ ) and also one control (without veneer inclusion). The Dunnett test (at 5\% of probability) was used in order to compare panels that went through veneer inclusion and control panels, while Scott-Knott (also at 5\% of probability) was performed to evaluate the type of wood and pressing pressure used in the process of veneer inclusion. 


\section{RESULTS AND DISCUSSION}

\section{Density and chemical analysis of the wood}

Table 1 presents mean values of basic density for each species used. It was observed that faveira wood presented the lowest mean basic density, while Eucalyptus urophylla presented the highest value.

Table 1. Basic density of wood species.

\begin{tabular}{cc}
\hline Wood species & Basic density (kg. m $\mathbf{- 3}$ \\
\hline Pinus oocarpa & $460(8,79)$ \\
Eucalyptus urophylla & $560(9,83)$ \\
Parkia gigantocarpa (faveira) & $280(9,86)$ \\
Brosimum parinarioides (amapá) & $420(5,72)$ \\
\hline \multicolumn{2}{c}{ The coefficient of variation is represented in brackets. }
\end{tabular}

The coefficient of variation is represented in brackets.

In relation to the chemical analysis of wood types (Table 2), it was observed that faveira wood presented the smallest amounts of extractives, but the larger percentage of holocellulose; the Eucalyptus urophylla wood highlighted because of the highest percentage of total extractives and lowest ashes content; the amapá wood presented the highest percentage of lignin and the smaller percentage of holocellulose, and the Pinus oocarpa wood, when compared to other species, presented intermediate values for all chemical components evaluated.

Table 2. Chemical analysis of wood species (\%).

\begin{tabular}{lcccc}
\hline \multicolumn{1}{c}{ Wood species } & Total extractive & Lignin & Ashes & Holocellulose \\
\hline Pinus oocarpa & $6,83(2,45) \mathrm{b}$ & $26,67(4,32) \mathrm{b}$ & $0,94(8,87) \mathrm{a}$ & $65,56(5,56) \mathrm{b}$ \\
Eucalyptus urophylla & $8,03(5,34) \mathrm{a}$ & $25,91(8,64) \mathrm{b}$ & $0,45(7,85) \mathrm{b}$ & $65,61(4,89) \mathrm{b}$ \\
Parkia gigantocarpa (faveira) & $3,52(9,39) \mathrm{c}$ & $25,08(9,57) \mathrm{b}$ & $0,98(16,27) \mathrm{a}$ & $70,42(3,77) \mathrm{a}$ \\
Brosimum parinarioides (amapá) & $5,31(16,67) \mathrm{b}$ & $30,51(1,12) \mathrm{a}$ & $0,88(14,66) \mathrm{a}$ & $63,30(1,57) \mathrm{c}$ \\
\hline
\end{tabular}

Means followed by the same letter did not differ by Scott - Knott test at $5 \%$ of significance.

The coefficient of variation is represented in brackets. 


\section{Physical properties of panels \\ Apparent density and moisture}

Table 3 shows the mean values of apparent density and moisture of panels for each treatment evaluated. It was observed that there were statistical differences among treatments when apparent density of panels was evaluated. Treatments produced with pine and amapá sheets at $2 \mathrm{MPa}$ of pressure and with eucalypt sheets at pressures ( 1 or $2 \mathrm{MPa}$ ) that differed statistically from control, obtaining higher values of apparent density. This fact is caused by the difference of density among sheets used on the inclusion (Table 1), as well as by the sheets pressing in the panel, including higher values of mean basic density of panels pressed at $2 \mathrm{MPa}$ in relation to those pressed at $1 \mathrm{MPa}$, what confirms the highest compression rate of the ready panel and also the sheet itself.

Analyzing moisture of panels, all treatments with veneer inclusion differed statistically from control (without inclusion), presenting higher mean values of moisture. This is associated to the greater amount of wood available for water absorption basically due to veneer inclusion.

Table 3. Apparent density and moisture of panels.

\begin{tabular}{ccc}
\hline Treatment & Apparent density $\left(\mathbf{k g}^{-m^{-3}}\right)$ & Moisture (\%) \\
\hline Pinus oocarpa_1MPa & $600(4,64) \mathrm{a}$ & $11,0(0,88) \mathrm{e}$ \\
Pinus oocarpa_2MPa & $660(2,39) \mathrm{b}$ & $10,6(1,00) \mathrm{c}$ \\
Eucalyptus urophylla_1MPa & $670(1,28) \mathrm{b}$ & $10,8(0,67) \mathrm{d}$ \\
Eucalyptus urophylla_2MPa & $740(3,73) \mathrm{c}$ & $10,5(1,52) \mathrm{b}$ \\
Parkia gigantocarpa_1MPa & $590(1,78) \mathrm{a}$ & $10,4(2,16) \mathrm{b}$ \\
Parkia gigantocarpa_2MPa & $620(3,38) \mathrm{a}$ & $10,4(0,20) \mathrm{b}$ \\
Brosimum parinarioides_1MPa & $640(4,40) \mathrm{a}$ & $10,3(1,04) \mathrm{b}$ \\
Brosimum parinarioides_2MPa & $680(1,14) \mathrm{b}$ & $10,3(1,54) \mathrm{b}$ \\
Control & $610(1,81) \mathrm{a}$ & $10,1(0,60) \mathrm{a}$ \\
\hline
\end{tabular}

Means followed by the same letter did not differ by Scott - Knott test at 5\% of significance. 


\section{Water absorption, thickness swelling and rate of non-return in thickness}

Table 4 presents mean values of water absorption after 2 and 24 hours of immersion for each treatment evaluated and the variation in relation to the treatment without veneer inclusion. It was observed that for WA2h only treatments with pine and amapá sheets at $1 \mathrm{MPa}$ did not present statistical difference in relation to control, the other treatments presented lower mean values of WA2h, differing statistically from panels without veneer inclusion. The reduction of mean values of WA2h with veneer inclusion ranged from 11,3 to $42,7 \%$.

Table 4. Mean values of water absorption.

\begin{tabular}{ccccc}
\hline \multirow{2}{*}{ Treatments } & WA2h & $\Delta$ & WA24h & $\Delta$ \\
\cline { 2 - 5 } & \multicolumn{4}{c}{$\%$} \\
\hline Pinus oocarpa_1MPa & $34,7(9,3) \mathrm{ns}$ & $-11,3$ & $55,4(4,3) \mathrm{ns}$ & $-4,2$ \\
Pinus oocarpa_2MPa & $29,4(9,0)^{*}$ & $-24,8$ & $44,9(3,2)^{*}$ & $-22,3$ \\
Eucalyptus urophylla_1MPa & $23,5(11,4)^{*}$ & $-39,9$ & $42,3(9,8) *$ & $-26,8$ \\
Eucalyptus urophylla_2MPa & $22,4(20,3)^{*}$ & $-42,7$ & $37,9(13,1)^{*}$ & $-34,4$ \\
Parkia gigantocarpa_1MPa & $29,7(12,7)^{*}$ & $-24,0$ & $56,5(8,4) \mathrm{ns}$ & $-2,2$ \\
Parkia gigantocarpa_2MPa & $25,5(11,1)^{*}$ & $-34,8$ & $51,9(1,6) \mathrm{ns}$ & $-10,2$ \\
Brosimum parinarioides_1MPa & $30,8(7,6) \mathrm{ns}$ & $-21,2$ & $51,8(8,2) \mathrm{ns}$ & $-10,4$ \\
Brosimum parinarioides_2MPa & $26,6(16,8) *$ & $-32,0$ & $45,1(12,5) *$ & $-22,0$ \\
\hline Control & $39,1(14,2)$ & \multicolumn{5}{c}{$57,8(6,4)$} \\
\hline
\end{tabular}

* It differs statistically from control by Dunnett test $(\alpha=0,05)$;

ns: It does not differ statistically from control by Dunnett test $(\alpha=0,05)$.

The coefficient of variation is represented in brackets.

For WA24h, only treatments with eucalypt sheets (1 and $2 \mathrm{MPa})$ pine (2 MPa) and amapá (2 MPa) differed statistically from panels without veneer inclusion, obtaining lower mean values for this property. The reduction of mean values of WA24h with veneer inclusion ranged from 2,2 to $34,4 \%$.

The reason for such improvement for the properties WA2h and WA24h may be related to two factors, the first regarding the barrier provided by the adhesive used for the sheet collage, what hampers the water penetration through the faces, and the second, as sheets were pressed with particle mattresses (particles used to produce OSB panels), there was a greater compression of the panel particles, diminishing empty spaces among them and causing the decrease of water absorption, what may be proved on Figure 3, in which it is observed that the increase of pressing pressure improves significantly both properties.

Table 5 presents the mean values of thickness swelling after two and 24 hours of immersion, the rate of non-return in thickness for each treatment evaluated, and the variation in relation to the treatment without veneer inclusion. It was observed for the property TS2h that panels with veneer inclusion with pine and eucalypt wood at $1 \mathrm{MPa}$ presented the lowest mean values, differing statistically from panels without veneer inclusion, with reduction of 22,2 and 20,4\%; respectively. Contrarily, panels with veneer inclusion with eucalypt, faveira and amapá wood at $2 \mathrm{MPa}$ presented the highest mean values for TS2h and differed statistically from control. The increase of TS2h values as pressure increased (2 MPa) may be explained by the harder pressing strength made on particles of the OSB panel mattress, since the veneer inclusion in harder pressures promotes a greater compressing of OSB panel particles, allowing a greater release of such pressing tensions, thus presenting more thickness swelling (Mendes et al. 2013). 
Table 5. Mean values of thickness swelling and rate of non-return in thickness.

\begin{tabular}{|c|c|c|c|c|c|c|}
\hline \multirow{2}{*}{ Treatments } & TS2h & $\Delta$ & TS24h & $\Delta$ & NRT & $\Delta$ \\
\hline & \multicolumn{6}{|c|}{$\%$} \\
\hline P. oocarpa_1MPa & $4,2(7,0) *$ & $-22,2$ & $8,1(5,4) *$ & $-32,5$ & $3,8(16,8) *$ & $-35,6$ \\
\hline P. oocarpa_2MPa & $6,1(7,0) \mathrm{ns}$ & 13,0 & $11,1(5,8) \mathrm{ns}$ & $-7,5$ & $7,3(6,0) *$ & 23,7 \\
\hline E. urophylla_1MPa & $4,3(13,7)^{*}$ & $-20,4$ & $9,3(4,5) *$ & $-22,5$ & $3,9(22,1)^{*}$ & $-33,9$ \\
\hline E. urophylla_2MPa & $7,3(20,4)^{*}$ & 35,2 & $12,6(25,8) \mathrm{ns}$ & 5,0 & $11,0(25,3) *$ & 86,4 \\
\hline P. gigantocarpa_ $1 \mathrm{MPa}$ & $4,8(10,8) \mathrm{ns}$ & $-11,1$ & $8,5(12,5) *$ & $-29,2$ & $4,9(21,4) \mathrm{ns}$ & $-16,9$ \\
\hline P. gigantocarpa_2MPa & $6,8(23,0) *$ & 25,9 & $12,1(22,2) \mathrm{ns}$ & 0,8 & $8,3(23,7) *$ & 40,7 \\
\hline B. parinarioides_1MPa & $4,9(9,7) \mathrm{ns}$ & $-9,3$ & $8,6(11,8)^{*}$ & $-28,3$ & $5,1(8,7) \mathrm{ns}$ & $-13,6$ \\
\hline B. parinarioides_2 $2 \mathrm{MPa}$ & $6,7(21,9) *$ & 24,1 & $11,0(15,4) \mathrm{ns}$ & $-8,3$ & $7,9(21,5) *$ & 33,9 \\
\hline Control & $5,4(20,2)$ & & $12,0(6,2)$ & & $5,9(6,8)$ & \\
\hline
\end{tabular}

For the property TS24h, independently of the wood type, the pressure of veneer inclusion at $1 \mathrm{MPa}$ promoted a significant reduction of thickness swelling in relation to control panels, presenting from 22,5 to $32,5 \%$ of decrease, while the pressure of veneer inclusion at $2 \mathrm{MPa}$ had not significant effect in relation to control. This indicates that the pressure $1 \mathrm{MPa}$ is ideal for veneer inclusion in OSB panels, since that in higher pressures, as $2 \mathrm{MPa}$, the compression tension provided to the panel causes more swelling, losing the efficiency of veneer inclusion.

In relation to NRT it was observed, as well as for TS2h, that panels with veneer inclusion with pine and eucalypt wood at $1 \mathrm{MPa}$ presented the lowest mean values, differing statistically from panels without veneer inclusion, with reductions of 35,6 and 33,9\%; respectively, in relation to control, while treatments at $2 \mathrm{MPa}$ differed statistically from panels without veneer inclusion for all the used species, presenting the highest mean values.

Further, according to statistical analysis, it was observed that there was not significant interaction between the factor wood type and pressing pressure for the properties WA2h, WA24h, TS2h, TS24h and NRT. However, within each factor, wood type (Figure 1 and 2) and pressing pressure (Figure 3), a significant effect was observed for some properties.

It was verified that the veneer inclusion with eucalypt wood provided the best results for the properties WA2h and WA24h, differing statistically from other wood types used. This may be related to a more closed anatomical structure, which is proved by the higher basic density of Eucalyptus urophylla (Table 1 ), as well as the highest extractive content of the species in relation to the others (Table 2).

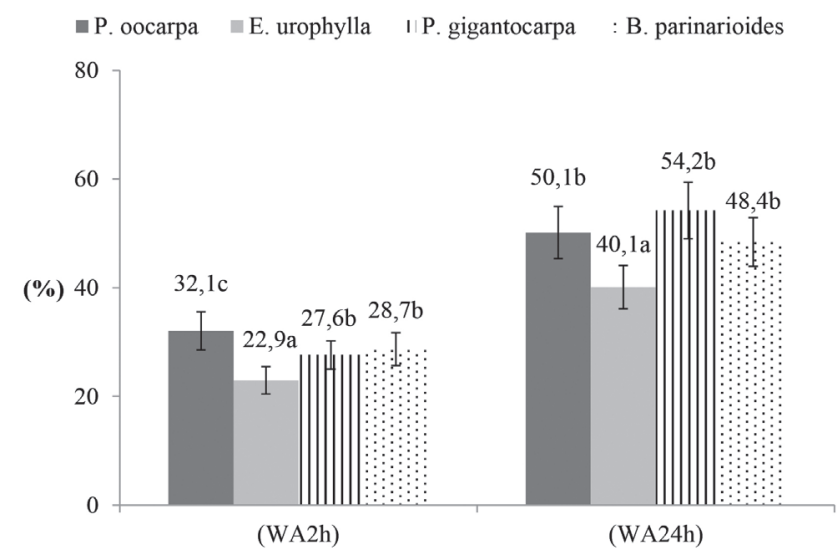

Figure 1. Water absorption in function of the wood type on veneer inclusion Means followed by the same letter did not differ by Scott-Knott test at $5 \%$ of significance. 
ఐP. oocarpa $\quad$ E. urophylla $॥$ P. gigantocarpa $\quad$ B. parinarioides

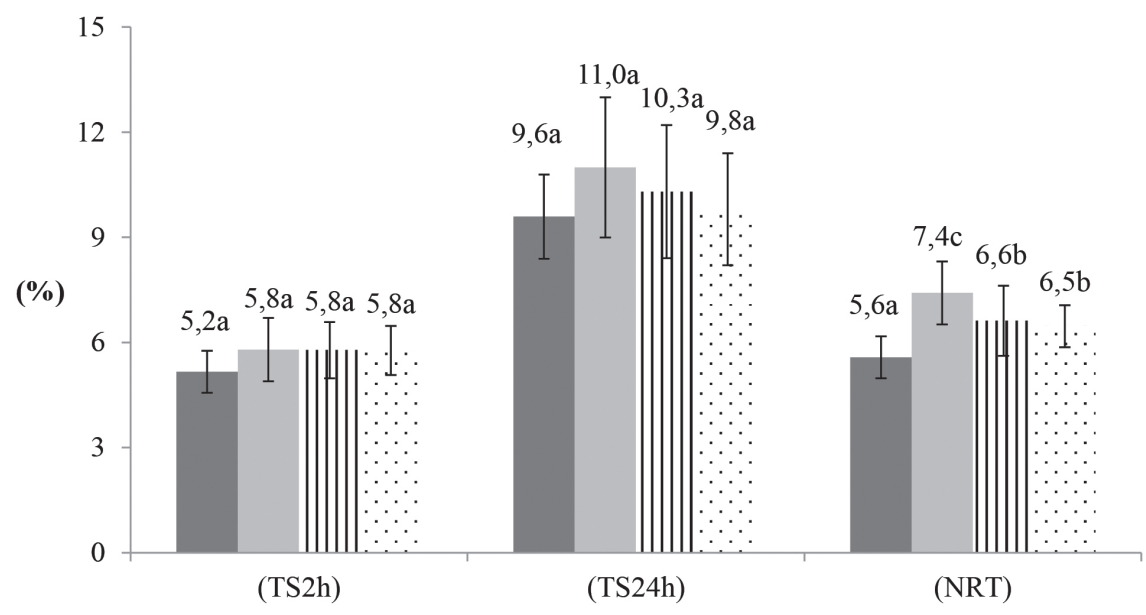

Figure 2. Thickness swelling and rate of non-return in thickness in function of the wood type used on veneer inclusion.

Means followed by the same letter did not differ by Scott-Knott test at 5\% of significance.

However, when the effect on the properties TS2h, TS24h and NRT (Figure 2) were evaluated, it was observed that the wood type did not affect significantly TS2h and TS24h, while for the property NRT treatments with eucalypt sheet presented the highest mean values, differing statistically the other species.

In relation to the pressure applied (Figure 3), independently of the wood type, since there was not interaction among the factors, it was observed that veneer inclusion at $2 \mathrm{MPa}$ differed statistically from the pressure $1 \mathrm{MPa}$ in all the physical properties evaluated, presenting the highest mean values for the properties, TS2h, TS24h and NRT, but causing the lowest mean values for the properties WA2h and WA24h.

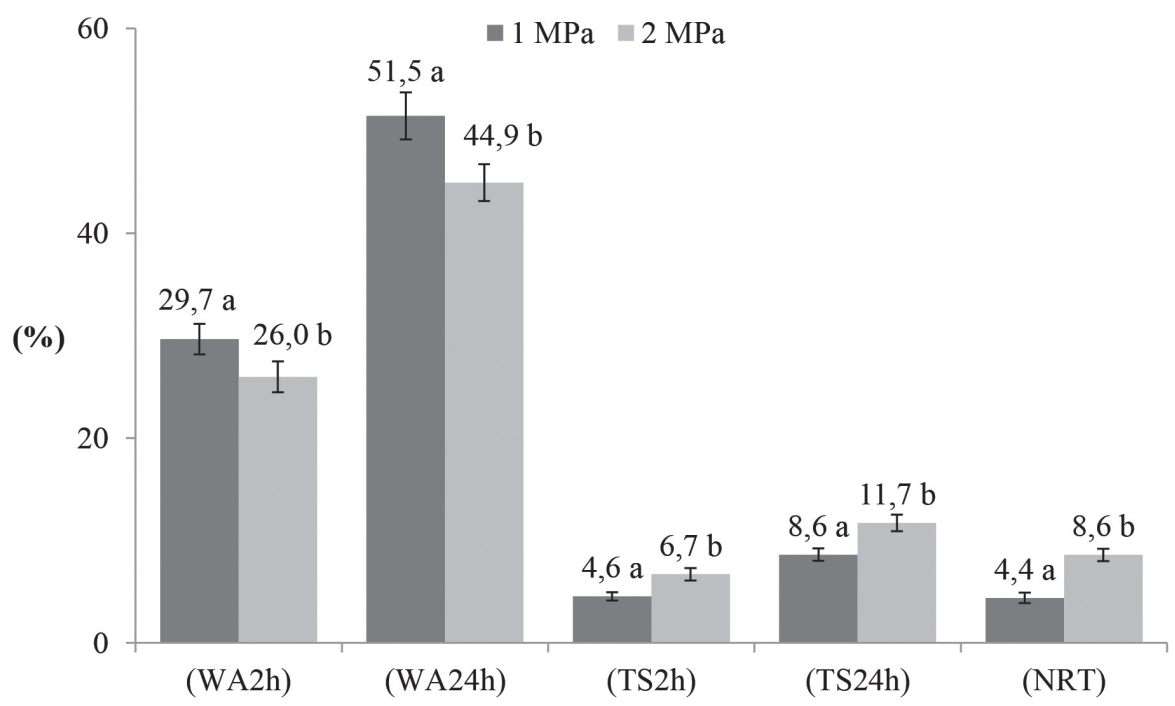

Figure 3. Water absorption, thickness swelling and rate of non-return in thickness in function of the pressure used on veneer inclusion.

Means followed by the same letter did not differ by Scott-Knott test at $5 \%$ of significance. 
Iwakiri et al. 2009, when evaluating the effect of veneer inclusion with Pinus taeda sheets and the pressing process for the production of OSB panels, did not observe significant effect of veneer inclusion on the water absorption properties and thickness swelling after 2 and 24 hours of immersion in water. However, a tendency to reduction of mean values of all evaluated physical properties was observed. Contrarily, Mendes et al. 2012, evaluated the effect of veneer inclusion with Pinus oocarpa sheets and of the pressing process on the production of OSB panels, and found a significant reduction only for the properties WA2h and TS2h, obtaining mean values of 80,3 and $26,4 \%$; respectively. But they did not observe such improvement for the properties WA24h, TS24h and NRT when panels were submitted to a longer time immersed in water. The authors explained this fact by greater compression of the particles of the panels with veneer inclusion. Because of this was increased the tension between the particles, which was maintained by the adhesive used, which was released, more prominently, when the panels were immersed in water for longer time. The authors obtained mean values of $104,3 \%$ for WA24h; $35,5 \%$ for TS $24 \mathrm{~h}$ and of $25,0 \%$ for NRT.

In this sense, the mean values obtained for physical properties in this study were smaller with those which were found in the literature. The improvement was because that the veneer inclusion in the panels was in consolidated panel (ready panels). While in the work found in literature the veneer inclusion is performed simultaneously with the pressing of OSB panels. However, when comparing with Canadian Standards Association" - CSA 0437 (1993), which determines the maximum value of TS24h at 10\%, only panels with veneer inclusion at $1 \mathrm{MPa}$, independently of the wood species, attended the standard. This demonstrates the functionality of veneer inclusion in OSB panels, what promotes an esthetical improvement as well as causes the significant reduction of TS24h, and this allows panel to adequate to the commercial standard.

\section{Mechanical properties of panels}

\section{MOR parallel and perpendicular}

Table 6 presents the mean values of modulus parallel and perpendicular rupture for each treatment evaluated and the variation in relation to the treatment without veneer inclusion. It was observed for MOR parallel that only treatments with veneer inclusion with eucalypt and amapá at 2 MPa promoted significant improvement in relation to the treatment without inclusion. The increase of mean values ranged was 36,7 and $39,6 \%$; respectively.

Table 6. Mean values of modulus of rupture

\begin{tabular}{ccccc}
\hline Treatments & $\begin{array}{c}\text { MOR parallel } \\
(\mathbf{M P a})\end{array}$ & $\boldsymbol{\Delta}$ & $\begin{array}{c}\text { MOR perpendicular } \\
(\mathbf{M P a})\end{array}$ & $\boldsymbol{\Delta}$ \\
\hline P.oocarpa_1MPa & $28,1(6,0) \mathrm{ns}$ & $-4,8$ & $19,9(8,7)^{*}$ & 45,3 \\
P. oocarpa_2MPa & $30,6(17,5) \mathrm{ns}$ & 3,7 & $21,3(6,5) *$ & 55,5 \\
E. urophylla_1MPa & $33,1(7,7) \mathrm{ns}$ & 12,0 & $22,6(10,8)^{*}$ & 65,0 \\
E. urophylla_2MPa & $36,7(5,2) *$ & 24,2 & $23,0(13,1)^{*}$ & 67,9 \\
P. gigantocarpa_1MPa & $21,9(15,5) *$ & $-25,8$ & $17,9(20,1)^{*}$ & 30,7 \\
P. gigantocarpa_2MPa & $18,2(7,1) *$ & $-38,3$ & $18,7(14,1)^{*}$ & 36,5 \\
B. parinarioides_1MPa & $34,2(26,5) \mathrm{ns}$ & 16,0 & $21,0(11,8) *$ & 53,3 \\
B. parinarioides_2MPa & $39,6(12,5) *$ \\
\hline \multicolumn{5}{c}{ Control $29,5(14,1)$} \\
\hline *It differs statistically from control by Dunnett test $(\alpha=0,05) ;$ \\
ns: It does not differ statistically from control by Dunnett test $(\alpha=0,05)$. \\
The coefficient of variation is represented in brackets.
\end{tabular}


However, veneer inclusion with faveira wood promoted a significant reduction of MOR parallel values, which was associated to the low basis density of the wood (Table 1) and consequently to the lower mechanical resistance of the sheets. For MOR perpendicular all treatments with veneer inclusion promoted significant improvement for this property. The increase of MOR perpendicular ranged from $30,7 \%$ to $78,1 \%$; what is justified by the fact that sheets were glued perpendicularly to the panels face.

It was also observed that there was not significant interaction between wood type and pressing pressure for MOR parallel and perpendicular. However, when each factor is individually analyzed, a significant difference is observed for the wood type (Figure 4) for both properties. A significant effect was not observed for pressing pressure on MOR parallel and perpendicular (Figure 5). It was observed for MOR parallel and perpendicular that eucalypt and amapá sheets obtained better results, differing statistically from pine and faveira wood. A significant difference also was observed between pine and faveira wood, in which faveira presented the lowest mean values. This is associated to the lower density of faveira wood (Table 1) and the consequent direct relation between density and mechanical resistance of the wood.

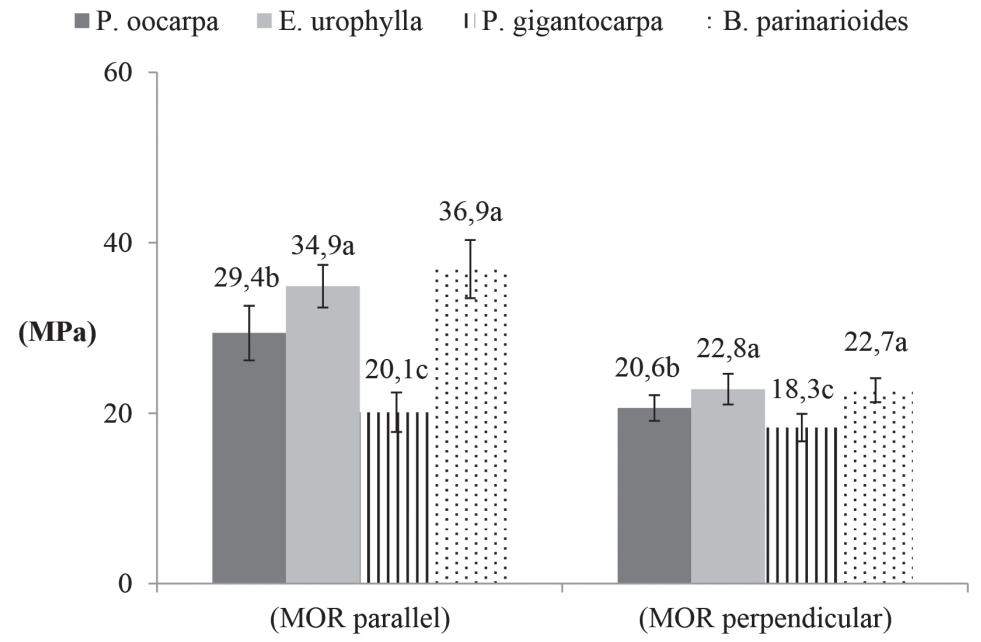

Figure 4. Modulus of rupture in function of the wood type used on veneer inclusion. Means followed by the same letter did not differ by Scott-Knott test at 5\% of significance.

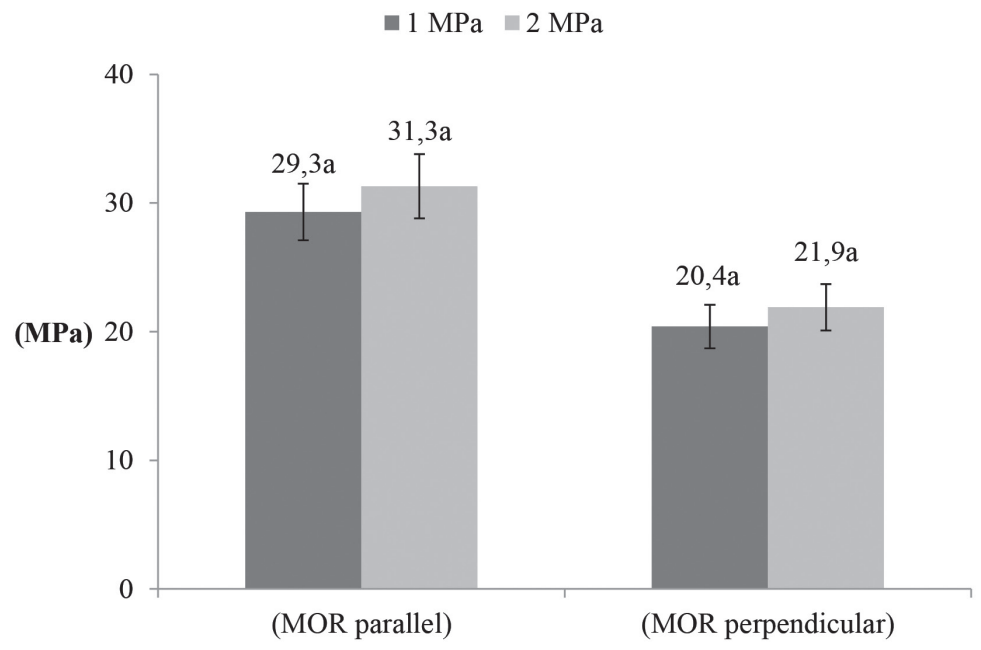

Figure 5. Modulus of rupture in function of the pressure used on veneer inclusion Means followed by the same letter did not differ by Scott-Knott test at 5\% of significance. 
Iwakiri et al. 2009, when evaluating the effect of veneer inclusion with Pinus taeda sheets and the pressing process for the production of OSB panels, observed a significant increase only for MOR perpendicular. Values obtained for OSB panels with veneer inclusion were 48,7 and 45,1 MPa for MOR parallel and perpendicular, respectively. The standard CSA 0437 (1993) determines minimum values of MOR parallel at 28,4 and 22,9 MPa for the classifications O-2 and O-1, respectively, while for MOR perpendicular these values are 12,2 and 9,4 $\mathrm{MPa}$, respectively.

In this sense, mean values obtained for these properties are below data found in the literature. However, when comparing to the standard CSA 0437 (1993), all treatments attended to the minimum determined by the O-2 classification, including a reasonable safety margin.

\section{MOE parallel and perpendicular}

Table 7 presents mean values of modulus of parallel and perpendicular elasticity for each treatment evaluated and the variation in relation to the treatment without inclusion. As well as observed for MOR parallel, veneer inclusion with faveira wood promoted significant reduction for MOE parallel, while other treatments caused significant improvement for this property. The increase of other three species (pine, eucalypt and amapá) for such property in relation to control ranged from 13,1 to $39,7 \%$.

Table 7. Mean values of modulus of elasticity.

\begin{tabular}{ccccc}
\hline Treatments & $\begin{array}{c}\text { MOE parallel } \\
\text { (Mpa) }\end{array}$ & $\boldsymbol{\Delta}$ & $\begin{array}{c}\text { MOE perpendicular } \\
\text { (Mpa) }\end{array}$ & $\Delta$ \\
\hline P. oocarpa_1MPa & $5839(18,6) *$ & 13,1 & $1889(5.2) *$ & 36,9 \\
P. oocarpa_2MPa & $6053(4,3) *$ & 17,3 & $1955(4,3) *$ & 41,7 \\
E. urophylla_1MPa & $6354(3,5) *$ & 23,1 & $2040(7,6) *$ & 47,8 \\
E. urophylla_2MPa & $7210(4,5) *$ & 39,7 & $2202(10,2) *$ & 59,6 \\
P. gigantocarpa_1MPa & $4399(6,3) *$ & $-14,8$ & $1643(8,9) *$ & 19,1 \\
P. gigantocarpa_2MPa & $4050(9,2) *$ & $-21,5$ & $1707(7,4) *$ & 23,7 \\
B. parinarioides_1MPa & $6478(17,7) *$ & 25,5 & $1999(8,0) *$ & 44,9 \\
B. parinarioides_2MPa & $6726(14,9)^{*}$ & 30,3 & $2225(11,9) *$ & 61,2 \\
\hline Control & $5161(12,4)$ \\
\hline
\end{tabular}

* It differs statistically from control by Dunnett test $(\alpha=0,05)$; ns: It does not differ statistically from control by Dunnett test $(\alpha=0,05)$. The coefficient of variation is represented in brackets. 
For MOE perpendicular all treatments with veneer inclusion presented significant improvements for this property, and the increase ranged from 19,1 to 61,2\%; what as well as MOR perpendicular is justified by the fact that sheets were glued perpendicularly to panels faces. It was also observed that there was a significant interaction between the factors wood type and pressing pressure for MOE parallel and perpendicular. However, when each factor was evaluated individually, a significant difference was observed for the wood type (Figure 6) for both properties. No significant effect was observed for pressing pressure (Figure 7). As well as for MOR, it was observed for MOE parallel and perpendicular that eucalypt and amapá sheets obtained the best results, differing statistically from pine and faveira wood. It was also observed a significant difference between pine and faveira, and the last one presented the lowest mean values.

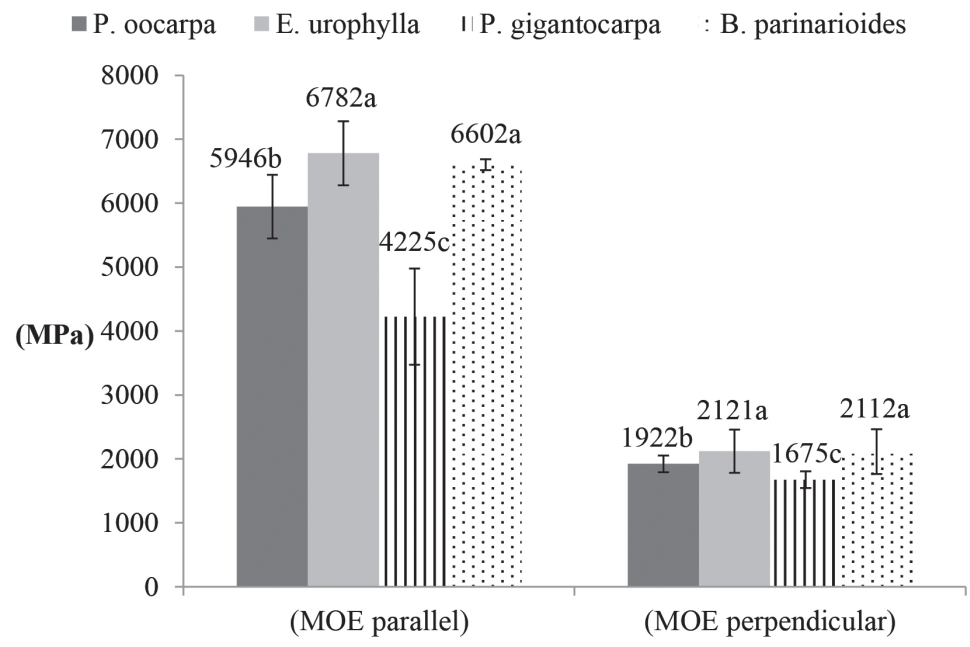

Figure 6. Modulus of elasticity in function of wood type used on veneer inclusion. Means followed by the same letter did not differ by Scott-Knott test at $5 \%$ of significance.

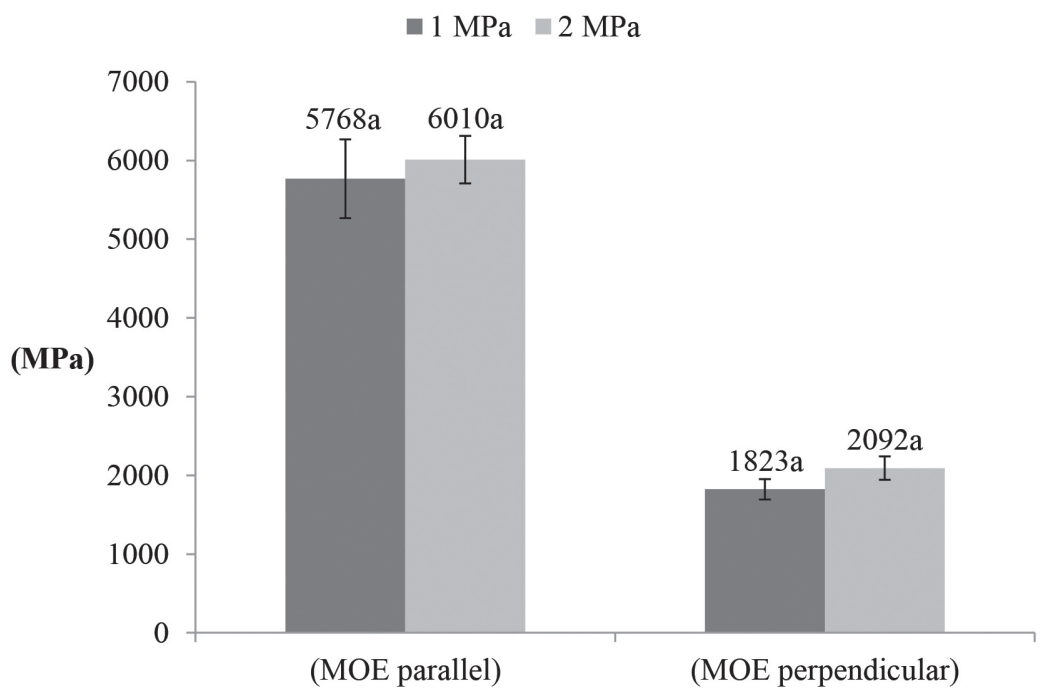

Figure 7. Modulus of elasticity in function of pressure used on veneer inclusion Means followed by the same letter did not differ by Scott-Knott test at 5\% of significance. 
Iwakiri et al. 2009, when evaluating the effect of veneer inclusion with Pinus taeda sheets and the pressing process for the production of OSB panels, observed a significant increase only for MOE perpendicular. Values obtained for OSB panels with veneer inclusion were 5937 and $5304 \mathrm{MPa}$ for MOE parallel and perpendicular, respectively. The standard CSA 0437 (1993) determines minimum values of MOE parallel 5393,7 and 4413 for the classifications O-2 and O-1, respectively, while for MOE perpendicular these values are 1471 and $1274,9 \mathrm{MPa}$, respectively.

In this sense, only mean values obtained for MOE parallel in this study are in accordance with data available in the literature, while the obtained MOE perpendicular was inferior. However, when comparing with the standard CSA 0437 (1993), treatments with veneer inclusion with pine, eucalypt and amapá wood attended the minimum determined by the O-2 classification for MOE parallel, while panels without inclusion attended the O-1 classification of the standard, and panels with inclusion with faveira wood did not attend the commercial standard. On the evaluation of MOE perpendicular all treatments with veneer inclusion attended the minimum determined by $\mathrm{O}-2$ classification, while panels without inclusion attended only the O-1 classification of commercial standard.

\section{CONCLUSIONS}

Generally, veneer inclusion with Pinus oocarpa, Eucalyptus urophylla and Brosimum parinarioides wood promoted significant improvements for physical-mechanical properties of the wood of OSB panels, highlighting eucalypt and amapá wood. Contrarily, faveira wood must not be used on veneer inclusion of OSB panels, since it presented significant reductions of MOR and MOE parallel.

There was not a significant effect of the pressure level on mechanical properties of OSB panels with veneer inclusion. However, for physical properties the highest pressure level ( $2 \mathrm{MPa}$ ) promoted negative effect on the properties TS2h, TS24h and NRT, while veneer inclusion at $1 \mathrm{MPa}$ promoted significant improvement of all physical properties, allowing that panels to adequate to the commercial standard CSA 0437 (1993), what was not possible for panels without inclusion.

In sum, optimal performance was obtained with eucalypt or amapá at a pressure of $1 \mathrm{MPa}$.

\section{ACKNOWLEDGMENTS}

The authors thank Universidade Federal de Lavras (UFLA) for supporting the experimental work, and also thank the financial support granted by Conselho Nacional de Desenvolvimento Científico e Tecnológico (CNPq) and Fundação de Amparo à Pesquisa do estado de Minas Gerais (FAPEMIG)-Brazil.

\section{REFERENCES}

ASTM D1037. 2006. Standard methods of evaluating properties of wood-base fiber and particles materials. American Society for Testing and Materials Annual book of ASTM standard. Annual Book of ASTM Standards, Philadelphia, pp. 1-30.

Avramidis, S.; Smith, L.A. 1989. The effect of resin content and face-to-core ratio on some properties of oriented strand board. Holzforschung 43 (2): 131-133.

Cabral, C.P.T.; Vital, B.R.; Della Lucia, R.M.; Pimenta, A.S.; Soares, C.P.B.; Carvalho, A.M.M. L. 2006. Propriedades de chapas tipo OSB, fabricadas com partículas acetiladas de madeiras de Eucalyptus grandis, Eucalyptus urophylla, Eucalyptus cloeziana E Pinus elliottii. Rev Árvore 30(4): 659-668. 
CSA 0437. 1993. OSB and waferboard. Canadian Standards Association, Ontario, 18 p.

Del Menezzi, C. H. S.; Tomaselli, I. 2006. Contact thermal post-treatment of oriented strand board to improve dimensional stability: a preliminary study. Holz als Roh und Werkstoff 64:212-217.

DIN 52362. 1982. Testing of wood chipboards bending test, determination of bending strength. DIN, Berlin, $40 \mathrm{p}$.

Garcia, R.A.; Cloutier, A.; Riedl, B. 2005. Dimensional stability of MDF panels produced from fibres treated with maleated polypropylene wax. Wood Science and Technology 39: 630-650.

Iwakiri, S.; Montefusco, A.R.G.; Zablonskyn, K.M.; Siqueira, K.P.; Saldanha, L.K.; Souza, M. A.M. 2003. Produção de chapas de partículas strand com inclusão laminar COM-PLAY. Floresta e Ambiente 10(2): 30-35.

Iwakiri, S.; Saldanha, L.K.; Albuquerque, C.E.C.; Mendes, L.M. 2009. Effects of particles thickness and veneer reinforced layer in the properties of oriented strand boards-0SB. Cerne 15(1):116-122.

Maloney, T.M. 1996. The family of wood composite materials. Forest Prod J 46(2): 19-26.

Mendes, R.F.; Mendes, L.M.; Carvalho, A.G.; Silva, A.F.A.; Guimarães JR, J.B. 2012. Effect of laminate inclusion and the type of adhesive in the properties of OSB panels of the wood from Pinus oocarpa. Brazilian Journal of Wood Science 3(2): 116-127.

Mendes, R.F.; Bortoletto JR, G.; Almeida, N.F.; Surdi, P.G.; Barbeiro, I.N. 2013a. Effect of thermal treatment on properties of OSB Panels. Wood Science and Technology 47(2): 243-256.

Mendes, R.F.; Bortoletto JR, G.; Almeida, N.F.; Surdi, P.G.; Barbeiro, I.N. 2013b. Effects of thermal pre-treatment and variables of production on properties of OSB panels of Pinus taeda. Maderas. Ciencia y Tecnologia 15(2): 141-152.

NBR 9531. 1986. Plywood - classification. ABNT- associação brasileira de normas técnicas, Rio de Janeiro, 3 p.

NBR 11941. 2003. Wood - Determination of basic density. ABNT- associação brasileira de normas técnicas, Rio de Janeiro, 6 p.

NBR 14853.2010. Wood - Determination of the material soluble in ethanol- toluene and dichloromethane and acetone. ABNT- associação brasileira de normas técnicas, Rio de Janeiro, 3 p.

NBR 7989. 2010. Pulp and wood: determination of acid insoluble lignin. ABNT- associação brasileira de normas técnicas, Rio de Janeiro, 6 p.

NBR 13999. 2010. Paper, paperboard and wood pulps: Determination of residue (ash) after ignition at $525^{\circ} \mathrm{C}$. ABNT- Associação brasileira de normas técnicas, Rio de Janeiro, 4 p.

Okino, E.Y.A.; Teixeira, D.E.; Del Menezzi, C.H.S. 2007. Post-thermal treatment of oriented strandboard (OSB) made from cypress (Cupressus glauca Lam.). Maderas. Ciencia y Tecnologia 9(3):199-210.

Paul, W.; Ohlmeyer, M.; Leithoff, H.; Boonstra, M.J; Pizzi, A. 2006. Optimising the properties of OSB by a one-step heat pre-treatment process. Holz als Roh und Werkstoff 64:227-234.

Tsoumis, G, 1991. Science and technology of wood. Structure, properties, utilization. Van Nostrand Reinhold, Greece.

Walker, J.C.F. 1993. Primary wood processing: principles and practice. Springer-verlag, London. 